\title{
Alkaline phosphatase immunoenzymatic staining for detection of antigens induced by cytomegalovirus
}

\author{
MONICA MUSIANI, MARIALUISA ZERBINI, M LA PLACA
}

From the Institute of Microbiology, University of Bologna Medical School, Ospedale S Orsola, Bologna, Italy

SUMMARY An indirect alkaline phosphatase immunoenzymatic staining method was developed to localise antigens in human embryo fibroblasts that have been induced by cytomegalovirus. The enzyme label was developed with a naphthol salt and fast blue to obtain a bright blue staining of the antigens that could be clearly visualised under an ordinary light microscope. The procedure is rapid, sensitive, and specific and can be used in diagnostic laboratories to detect active infection caused by cytomegalovirus.

In cells infected with human cytomegalovirus several antigens appear at varying intervals. Before replication of viral DNA cytomegalovirus induces the appearance of immediate early ${ }^{1}$ and early antigens, ${ }^{2}$ which are present in the nuclei of infected cells one and 24 hours after infection, respectively. About 72 hours after infection, at the end of the cytomegalovirus replication cycle, late antigens can be detected in the nucleus and cytoplasm of infected cells. ${ }^{3}$ The immune response to antigens induced by cytomegalovirus is widely used for serological diagnosis of cytomegalovirus infection, and the presence of these antigens in cell cultures infected by clinical specimens, or in tissue sections, has always been considered to be a marker of viral infection.

The need for a rapid and sensitive method to diagnose cytomegalovirus infection has led to the use of immunoenzymatic stainings in cell cultures or tissue sections suspected of harbouring the virus. Until now the immunoperoxidase technique has been the preferred system to localise antigenic constituents in infected cells, ${ }^{45}$ but many cells contain endogenous peroxidase activity which can impair the specific immunoperoxidase labelling reaction. As alkaline phosphatase can also be used in immune labelling methods ${ }^{6-8}$ our study aimed to develop an alkaline phosphatase indirect immunoenzymatic assay to stain and localise the different antigens induced by cytomegalovirus in infected human fibroblasts.

Accepted for publication 29 May 1985

\section{Material and methods}

Human embryo fibroblasts were grown in Eagle's minimum essential medium supplemented with $10 \%$ fetal calf serum and antibiotics. The Towne strain of human cytomegalovirus was used in all the experiments. Stock virus was propagated at low multiplicity of infection and harvested three to four days after $100 \%$ cytopathic effect. ${ }^{9}$ Virus infection in human embryo fibroblasts grown on coverslips was carried out with one plaque forming unit cell, with an adsorption period of two hours. ${ }^{10}$ Cells infected by cytomegalovirus and mock infected controls were fixed in acetone for 15 minutes at $4^{\circ} \mathrm{C}$ at various intervals after infection (one, 24, 36, 72 hours). Moreover, infected cells were treated with $75 \mathrm{ug} / \mathrm{ml}$ of the DNA inhibitor cytosine arabinoside (Ara C) and fixed in acetone at 72 hours after infection to allow early antigens to accumulate.

Monoclonal antibody against immediate early antigens to cytomegalovirus (Biotech, United States) and human reference sera positive for early and late antigens induced by cytomegalovirus (FG 182: early antigens $1 / 320$, late antigens $1 / 320$; AC 203: early antigens negative, late antigens $1 / 320$ ) were used in the immunoalkaline phosphatase test to detect immediate early antigens in cells fixed one hour after infection; early antigens in cells fixed 24 , 36 , and 72 hours after infection when treated with cytosine arabinoside; and late antigens in cells fixed at 72 hours after infection. Infected cells fixed with acetone and relative controls were treated with reference sera positive for the antigens induced by cytomegalovirus at $37^{\circ} \mathrm{C}$ for 45 minutes. After three 

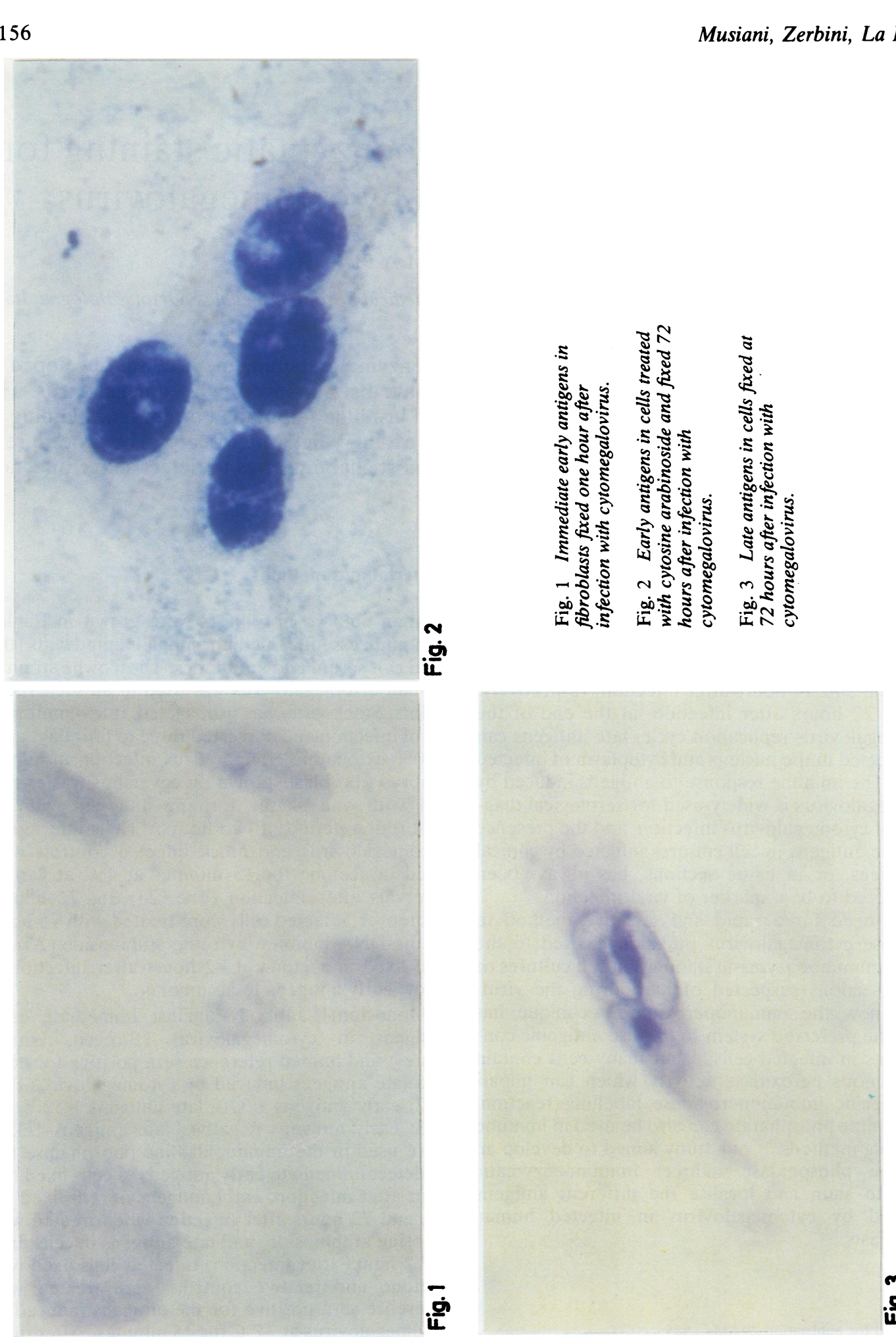
washes in phosphate buffered saline $0 \cdot 1 \mathrm{M}, \mathrm{pH} 7 \cdot 4$, phosphatase labelled antibody to human IgG or to mouse IgG (when monoclonal serum was used) was added at the dilution of $1 / 20$. Cells were then incubated at $37^{\circ}$ for 45 minutes, and after three further washes in phosphate buffered saline the alkaline substrate was added.

The alkaline phosphatase substrate was prepared by dissolving $2 \mathrm{mg}$ of naphthol AS phosphate in $0.2 \mathrm{ml}$ of dimethylformamide in a glass tube and then adding $9.8 \mathrm{ml}$ of $0.1 \mathrm{M}$ Tris hydrochloric acid buffer, $\mathrm{pH}$ 9. Immediately before this preparation was used fast blue RR was added at a concentration of $1 \mathrm{mg} / \mathrm{ml}$ and the solution filtered directly on to the slide. The development of the coloured reaction product was monitored by microscopic examination of the slides during the staining procedure, the reaction being stopped when optimal contrast was achieved. The slides were then washed in phosphate buffered saline and mounted in $80 \%$ glycerol.

\section{Results}

Antigens induced by cytomegalovirus were visualised with a dark blue precipitate obtained by developing the alkaline phosphatase label with a naphthol salt as a coupling agent in the presence of a diazonium salt (fast blue) as a capture agent. In human fibroblasts fixed one hour after infection with cytomegalovirus and treated with monoclonal antibody against immediate early antigens positive nuclei were detected with a good labelling intensity in positive cells. (Fig. 1). In cells fixed at 24 and 36 hours after infection early antigens were present in the nuclei of infected cells, but a sharper localisation of the reaction product was observed when early antigens had accumulated in infected cells after treatment with cytosine arabinoside for 72 hours (Fig. 2). In infected human fibroblasts fixed at the end of the cytomegalovirus replication cycle (72 hours after infection) late antigen positive cells were seen with nuclear and cytoplasmic inclusions (Fig. 3 ). In control cells treated with sera positive for cytomegalovirus no specific staining was noted.

\section{Discussion}

The indirect alkaline phosphatase immunoenzymatic staining procedure reported here specifically detects and stains antigens induced by cytomegalovirus in infected cells yet does not stain uninfected control cells. In this assay the bright blue colour of the reaction product makes positively labelled antigens stand out with great clarity and can provide a permanent record easily viewed in an ordinary light microscope. Moreover, immunoalkaline phosphatase staining avoids problems due to endogenous peroxidase activity, which sometimes arise when tissues are stained by immunoperoxidase methods. In fact, as endogenous peroxidase activity results in non-specific staining and can confuse diagnostic interpretations specimens are often pretreated with hydrogen peroxide or other reagents to eliminate the endogenous enzymatic activity. Pretreatments, however, increase the staining time, can alter the antigenic activity, and decrease the sensitivity of the assay. 112

Our findings suggest that the immunoalkaline phosphatase staining we describe fulfils the criteria of a practical, rapid, and reliable assay for detecting antigens induced by cytomegalovirus in infected cells. This staining procedure can also be applied in the serological diagnosis of active cytomegalovirus infection by examining the immune state against the different antigens induced by cytomegalovirus.

The skilful technical help of Miss Marinella Plazzi is gratefully acknowledged. This work was partially supported by a CNR Progetto Finalizzato Controllo delle Malattie da Infezione grant No 84.02007.52.

\section{References}

' Michelson-Fiske S, Horodniceanu F, Guillon JC. Immediate early antigens in human cytomegalovirus infected cells. Nature 1977;270:615-7.

2 The TH, Klein G, Langenhuysen MMAC. Antibody reaction to virus-specific early antigens (EA) in patients with cytomegalovirus (CMV) infection. Clin Exp Immunol 1974; 16: 1-12.

${ }^{3}$ Rapp F, Rasmussen LE, Benyesh-Melnick M. The immunofluorescent focus technique in studying the replication of cytomegalovirus. J Immunol 1963;91:709-19.

4 Gerna G, Vasquez A, McCloud CJ, Chambers RW. The immunoperoxidase technique for rapid human cytomegalovirus identification. Arch Virol 1976;50:311-21.

s Gerna G, Chambers RW. Rapid detection of human cytomegalovirus and herpesvirus hominis IgM antibody by the immunoperoxidase technique. Intervirology 1977;8:257-61.

- Avrameas S. Coupling of enzymes to proteins with glutaraldehyde. Use of the conjugates for the detection of antigens and antibodies. Immunochemistry 1969;6:43-52.

' Pepys EO, Pepys MB. Enumeration in whole peripheral blood of lymphocytes bearing receptors for $\mathrm{Fc}$ and $\mathrm{C} 3 \mathrm{~b}$ using alkaline phosphatase labeling reagents. J Immunol Methods 1980;32:305-9.

${ }^{8}$ Musiani M, Carpi C, Zerbini M. Rapid detection of antibodies against cytomegalovirus induced immediate early and early antigens by an enzyme linked immunosorbent assay. $J$ Clin Pathol 1984;37:122-5.

${ }^{y}$ Musiani M, Zerbini M. Influence of cell cycle on the efficiency of transfection with purified human cytomegalovirus DNA. Arch Virol 1984; 78:287-92.

10 Musiani M, Landini MP, Feletti C, La Placa M. Serum antibodies against cytomegalovirus induced early and immediate early antigens and presence of viruria in renal transplant recipients. Microbiologica 1978;1:101-5.

"Streefkerk JG. Inhibition of erythrocyte pseudoperoxidase activity by treatment with hydrogen peroxide following methanol. $J$ Histochem Cytochem 1972;20:829-34.

12 Weir EE, Pretlow TG, Pitts A, William EE. Destruction of endogenous peroxidase activity in order to locate cellular antigens by peroxidase labeled antibody. J Histochem Cytochem 1974;22:51-6.

Requests for reprints to: Dr Monica Musiani, Institute of Microbiology, 9, via Massarenti, 40138, Bologna, Italy. 